\title{
A Fault Detection Technique for Series-compensated Lines by TCSC during Power Swing
}

\author{
Saeed Rezaei ${ }^{1}$, Mojtaba Khederzadeh ${ }^{2}$, Majid Gandomkar ${ }^{3}$ \\ ${ }^{1,3}$ Faculty of Electrical Engineering Department, Islamic Azad University of Saveh, Iran \\ ${ }^{2}$ Faculty of Electrical Engineering Department, Shahid Beheshti University, Iran
}

\begin{tabular}{l} 
Article Info \\
\hline Article history: \\
Received Jun 30, 2017 \\
Revised Jan 9, 2018 \\
Accepted Feb 20, 2018 \\
\hline
\end{tabular}

\section{Keyword:}

Distance relaying

Fault detection

Power swing

TCSC (Thyristor Controlled

Series Capacitor)

\begin{abstract}
The performance of a distance relay is very susceptible to power swing. In order to avoid generating unwanted trip in such condition, a power swing block function (PSB) is used in distance relays. However, if a fault occurs in power swing condition, the relay should distinguish the fault from power swing and generate trip rapidly. Detection a fault in a series-compensated line by Series Capacitor (SC) during the power swing is more complicated than in an uncompensated line due to complex transients generated by series capacitor and the Metal-Oxide Varistor (MOV) operation. In a seriescompensated line by TCSC, it is further complicated due to nonlinear variation of compensation level during power swing and fault, moreover, non-unique application mode of TCSC for different faults which is dependent on fault current. This paper examines a method based on negative sequence current to detecting all types of fault during power swing in a series-compensated line by TCSC. The method is tested for different TCSC-compensated power systems include SMIB and 9-bus 3-machine systems. Different types of faults, i.e., symmetrical, asymmetrical and high resistance faults occurring during a power swing are simulated by MATLAB/SIMULINK to examine the algorithm.
\end{abstract}

Copyright $@ 2018$ Institute of Advanced Engineering and Science. All rights reserved.

\section{Corresponding Author:}

Saeed Rezaei,

Department of Electrical and Computer Engineering,

Islamic Azad University of Saveh,

Felestin Sqr., Saveh, Markazi province, Iran

Email: saeedrezaei2255@gmail.com

\section{INTRODUCTION}

The fast development of power electronic technology has many possibilities to use new equipments in order to improve utilization of existing systems. During the past decade, several control equipments as Flexible AC Transmission Systems (FACTS), have been designed and implemented. FACTS devices can be used in order to control the power flow, voltage regulation, ambulatory power control, transient stability and damping oscillations of power systems. One of the series FACTS devices is Thyristor Controlled Series Capacitor (TCSC) that is used for improve transmission capacity on long lines. Although using TCSC, improves power transmission's capacity and system's stability, it can causes problems in power system's protection, especially distance protection [1-2].

Power systems in steady state operation, maintain a balance between generation and loads. In this condition the rotor's angle of all generators don't change and they are fixed. If a disturbance occurs in the system, such as switching on fault, On/off generators and large loads, the generator's rotor angles oscillate to find a new stable point. This phenomenon is known as power swing, which can cause generate unwanted trip in distance relays. Get out the line from productivity, adds more disturbance to the status quo. This unwanted trip in power swing condition, will be even harder power grids conditions for maintaining the stability. So in 
order to maintain system stability, power swing blocking function (PSB) in distance relays is considered that will block the distance units when detects a power swing [3].

If a fault occurs in a power swing condition, the distance relay must detect the fault and generate trip as soon as possible. Detection of faults during a power swing in a series compensated line is more complicated than in an uncompensated line, due to generation of various frequency components in the fault signals which are depend on the fault type, fault location, level of compensation and performance of Varistor Metal Oxide (MOV) [4]. Also, in a series compensated line by TCSC, it is more complicated than SC compensated line due to nonlinear variation of compensation level and un-unique application mode of TCSC for different faults that is related to fault current [5]. This imposes difficulty to distinguish faults from power swing. There are several available techniques to detect faults during power swing in uncompensated transmission lines [6-12], that they have limitations in presence of series compensation due to the nonlinear functioning of the series compensator combination [13-14].

A technique in the basis of the magnitude of swing-center voltage (SCV) and its rate is presented to detection faults during power swing [6]. A method based on voltage phase's angle monitoring at the relay location is available to detecting high-resistance ground faults during power swing [7]. A fault detection method based on superimposed components of current is presented in [8]. A method depended on estimated rate of change of resistance at the relay location is used to detection faults during the power swing [9]. In [10], a cross-blocking method based on derivative of the three-phase active and reactive power is presented to distinguish symmetrical faults from power swing.

A symmetrical fault detector scheme is presented on the basis of decaying dc presence in current waveforms during the power swing [11]. A method using adaptive Neuro-Fuzzy Inference System (NFIS) is proposed in [12]. This method has limited performance to detection faults during fast power swing and it needs a large number of training patterns. In [13], the evaluation and performances comparison of different power swing detection methods for a series-compensated line has been studied. The Results show that the decreasing impedance algorithm works better for the series capacitor compensated transmission line. In [14], a method based on negative sequence current for detecting fault during power swing in compensated lines by Series Capacitors is presented. The method is compared with the available techniques and it is found that it is accurate and fast in detecting the faults during the power swing.

In this paper, the aforesaid technique is extended to be applicable in TCSC-compensated systems. The proposed method is tested on Single Machine Infinite Bus (SMIB) system and also on a 9-bus 3-machine power system. Different types of faults occurring during the power swing: symmetrical, asymmetrical, and high resistance faults are simulated by MATLAB/SIMULINK to validate the algorithm.

\section{RESEARCH METHOD}

The basic operation of TCSC can be explained from the circuit analysis easily. It consists of a series compensating capacitor shunted by a Thyristor Controlled Reactor (TCR). TCR is a variable inductive reactor $\mathrm{X}_{\mathrm{L}}(\alpha)$ controlled by firing angle $\alpha$. (Figure 1 ).

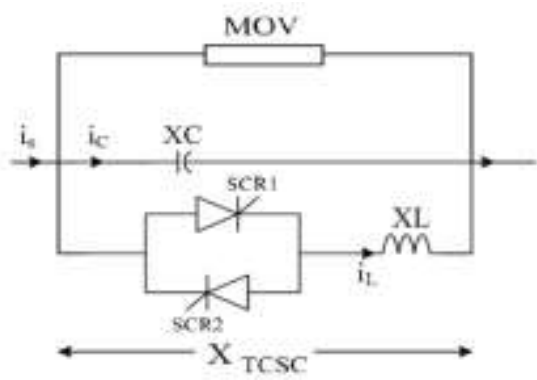

Figure 1. Equivalent circuit of TCSC

Variation of $\mathrm{X}_{\mathrm{TCSC}}$ with respect to $\alpha$ is given by:

$$
\mathrm{X}_{\mathrm{TCSC}}(\alpha)=\frac{\mathrm{X}_{C} \cdot \mathrm{X}_{L}(\alpha)}{\mathrm{X}_{L}(\alpha)-\mathrm{X}_{C}}
$$

Where:

$$
X_{L}(\alpha)=X_{L} \frac{\pi}{\pi-2 \alpha-\sin 2 \alpha} \quad \mathrm{X}_{\mathrm{L}} \leq \mathrm{X}_{\mathrm{L}}(\alpha) \leq \infty
$$


For the range of 0 to 90 of $\alpha, \mathrm{X}_{\mathrm{L}}(\alpha)$ start vary from actual reactance $\mathrm{X}_{\mathrm{L}}$ to infinity. This controlled reactor is connected across the series capacitor, so that the variable capacitive reactance is possible across the TCSC to modify the transmission line impedance [15].

\subsection{Impedance characteristics}

Figure 2 shows the impedance characteristics curve of a TCSC device. As can be deduced from this figure, the impedance characteristics of a TCSC can be in both capacitive and inductive region through varying firing angle $(\alpha)[16]$.

\subsection{Different possible TCSC modes of operation during a fault}

Different possible TCSC modes of operation during a fault can be summarize as follows:

Capacitive-boost mode without MOV conduction: For a low current of far end or high resistance faults, the protection function of the TCSC device does not work; therefore the TCSC remains constantly in its vernier mode of normal operation.

Capacitive-boost mode with MOV conduction: For a high fault current, where the fault current exceeds MOV operation threshold and it is not enough for TCSC change mode operation, MOV operates for decreasing the voltage across the capacitor. The MOV is fast enough to conduct and reset within a half cycle. The MOV would not short circuit out the capacitor as the circuit breaker would. This condition is usually very short but may be repeated several times during the fault period.

Blocking mode: When the thyristors are not triggered and are kept in non-conducting state, the TCSC is operating in blocking mode. In this mode, the TCSC performs like a fixed series capacitor. When the TCSC detects an overvoltage by the MOV current, the TCR branch stops its firing sequence by a protection function. The process is effective for avoiding the over current of the thyristors or capacitor caused by fluctuation of the firing angle under the condition that the voltage phase of the capacitors changes suddenly.

Bypass mode: In this mode, the thyristors are triggered continuously and the TCR branch conducts in the whole in order to limits the current of solid and near source faults, where the fault's current exceeds the TCSC change mode threshold. In this mode the TCSC voltage decrease extremely and MOV operation is not needful [5].

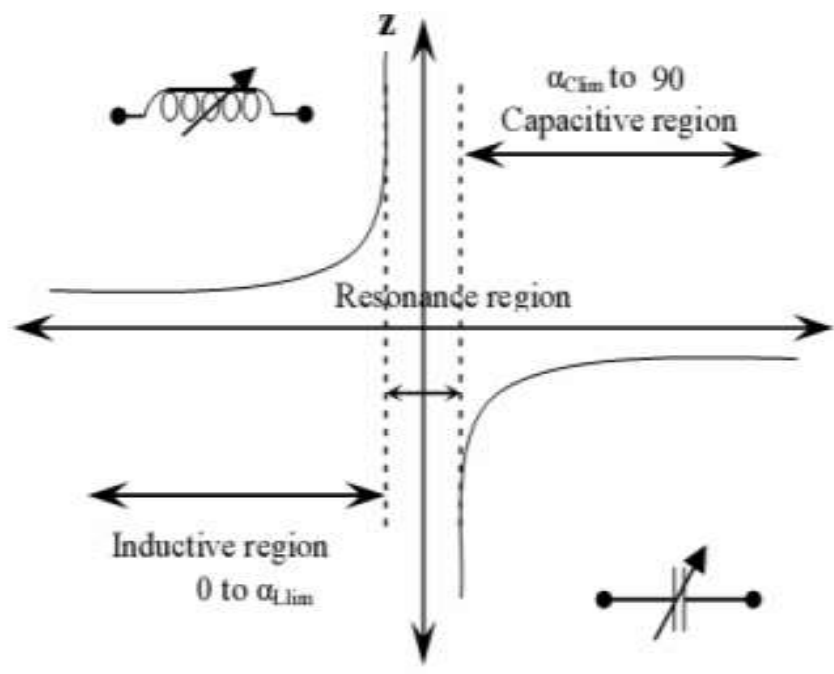

Figure 2. Impedance characteristics curve of a TCSC: $0<\alpha<\alpha_{\text {clim }}=$ inductive region; $\alpha_{\text {Llim }}<\alpha<$ $\alpha_{\text {Clim }}=$ resonance region and $\alpha_{\text {clim }}<\alpha<90=$ capacitive region.

\subsection{Proposed fault detection technique}

Power swing is a balanced phenomenon, but a small percentage of negative-sequence components of current $\left(\mathrm{I}_{2}\right)$ is found due to signal modulation and the related phasor computation technique. For unbalanced faults during the power swing, a significant amount of negative-sequence current is observed. In case of a three-phase fault during the power swing, negative-sequence current is observed at the initial period of the fault due to transients in the current signals and in the subsequent period due to the presence of modulated 
frequency components by the power swing [14].

It is evident from the previous discussion that negative-sequence current is available in the computation process during the swing. But with a small amount of remaining during the swing condition, a change in the magnitude of the negative-sequence current $\left(\Delta \mathrm{I}_{2}\right)$-based technique suits the purpose. With a suitable threshold, the cumulative sum of the $\Delta \mathrm{I}_{2}$-based technique is selected in this paper for the fault detection during swing. A cumulative sum (CUSUM) is a versatile technique used for abrupt change detection in various fields [17]. It is to be noted that the CUSUM-based approach is applied for transmissionline fault detection using sampled values of the current signal [18] and has limitations due to uneven variation in sample-to-sample magnitude difference of current during power swing. In this paper, CUSUM is applied to obtain a good index for fault detection during the power swing where a change in negativesequence current is being used as the input signal. The computation steps for the method are provided:

$$
\bar{I}_{2}=\frac{\left.\overline{(I}_{a}+\alpha^{2} \bar{I}_{b}+\alpha \bar{I}_{c}\right)}{3}
$$

Where $I_{2}$ is the negative-sequence current; $\alpha=e^{j 2 \pi / 3} ; I_{a}$ and $I_{b}$ and $I_{c}$ are the phase currents. A derived signal is obtained as:

$$
S_{k}=\Delta\left|\bar{I}_{2 k}\right|=\left|\bar{I}_{2 k}\right|-\left|\bar{I}_{2 k-1}\right|
$$

For $\mathrm{S}_{\mathrm{k}}>\varepsilon$, the proposed CUSUM test is expressed as:

$$
g_{k}=\max \left(g_{k-1}+S_{k}-\varepsilon, 0\right.
$$

where the index $g_{k}$ represents the test statistics and is the drift parameter in it. A fault is registered if:

$$
g_{k}>\mathrm{h}
$$

Where $\mathrm{h}$ is a constant and should be ideally zero. In (4), $\varepsilon$ provides the low-pass filtering effect and influences the performance of the detector. When $S_{k}>\varepsilon$, the $g_{k}$ value increases by a factor of the difference between $g_{k}$ and $\varepsilon$. With further current samples available, the CUSUM process provides an easy way to decide on the fault situation by applying (5).

After each fault detection index, $\mathrm{g}_{\mathrm{k}}$ is reset to zero. For only the swing situation, $\mathrm{g}_{\mathrm{k}}$ will be zero as $\Delta \mathrm{I}_{2}<\varepsilon$. The selection of $\varepsilon$ and $\mathrm{h}$ is important for determining the performance of the algorithm. It is already demonstrated that though the power swing is a balanced phenomenon, a small amount of negativesequence component of current is observed in the phasor extraction process which increases slowly with an increase of swing cycle slip frequency [14]. In the proposed CUSUM-based fault detection technique, the value of $\varepsilon$ is set to make $S_{k}=0$ during swing (both stable and unstable) which finally helps to maintain the fault detector index $g_{k}=0$.

In this paper, the setting of $\varepsilon=0.2$. The value of $h$ is set such that the algorithm can maintain the balance between dependability versus security and speed versus accuracy requirements of the relaying scheme. In this paper, the value of $h$ is set at 0.35 , considering all force fault situations during the power swing, for example, high resistance faults occurring at the far end of the line when $\delta$ is close to 180 (the change in magnitude of fault current is low; dependability issue) as well as non fault situations such as load change and capacitor switching (security issue) such that the proposed technique can distinguish faults from other events correctly. The proposed method is based on the CUSUM approach and, therefore, a distinctly much higher index value $\mathrm{g}_{\mathrm{k}}$ is obtained during the fault.

This fault detection algorithm is tested for different faults, during the power swing in compensated systems by TCSC. Using MATLAB/SIMULINK with distributed parameter line model, data was generated. The current inputs to the distance relay are fed from the secondary of a current transformer with 1000:5 turn ratios. The nonlinear CT model is considered in the simulations. Also in order to estimate the fundamental component a least-square technique with decaying dc component is used. A window of one-cycle data samples is considered for each phasor computation and data-sampling rate is modified at $1 \mathrm{kHz}$ for the $50-\mathrm{Hz}$ power system. Sequence components were estimated considering phase-a as reference. The convention used in this paper is such that the output of the algorithm should be ' 1 ' for fault and ' 0 ' for the no-fault situation. 


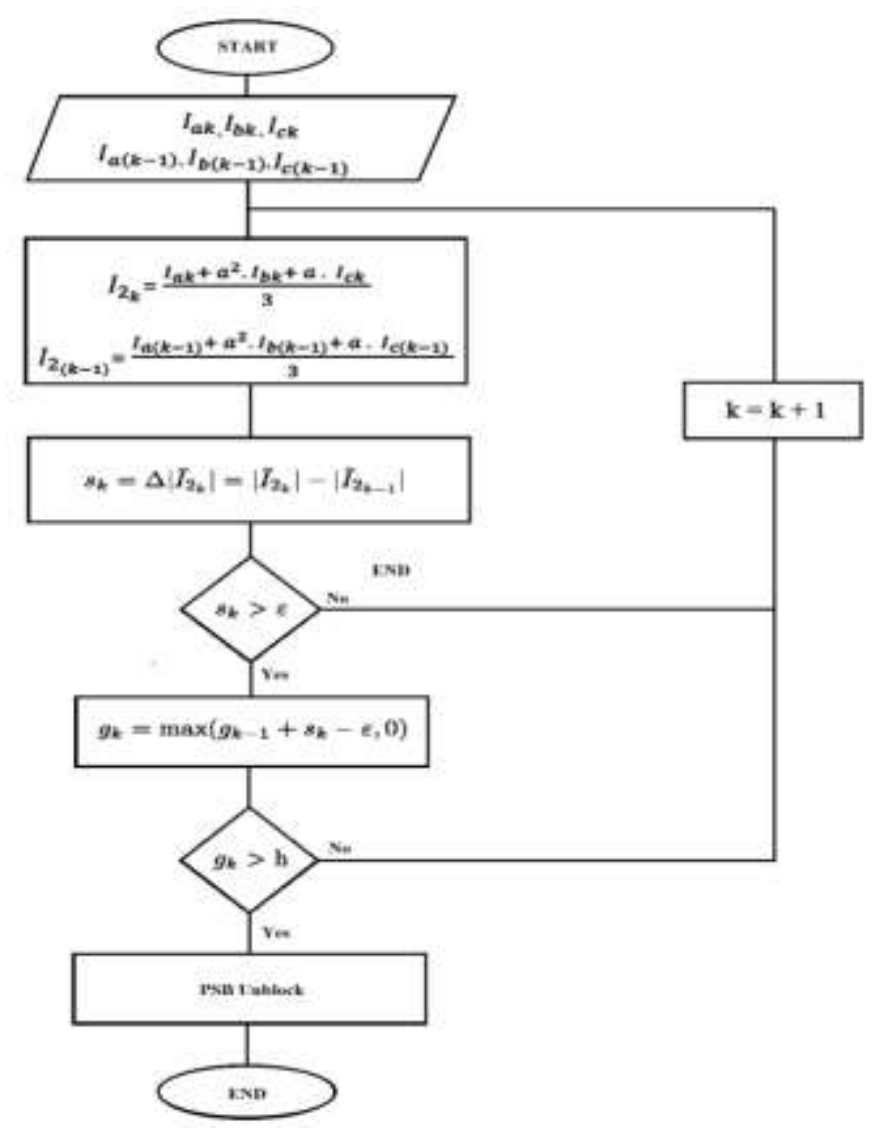

Figure 3. Proposed technique flowchart

\section{RESULTS AND ANALYSIS}

In order to demonstrate the fault detection issues during power swing in a series-compensated line by TCSC, a test system [14] shown in Figure 4 is considered. Both Line-1 and Line-2 are 75\% compensated by TCSC (when Thyristor switch is open or $\alpha=90$ degree) and the Compensators are placed at the mid-point of lines. The protection scheme of each series capacitor including an MOV is shown in Figure 4. The system details are provided in Appendix A. The system with the distributed line model is simulated using MATLAB/SIMULINK. The power angle $\delta$ here refers to the angle between the voltages at buses $\mathrm{M}$ and $\mathrm{N}$. The distance relay $\mathrm{R}$ for breaker B1 is considered for the study. A three-phase fault with $0.001 \Omega$ resistance is created at the near end of Line- 2 at $5 \mathrm{~s}$ and cleared at $5.150 \mathrm{~s}$ by opening breakers B 3 and B4. This causes a significant power swing condition in Line-1 and it is observed by the relay R. During this condition, line 1 transfer power, three phase current and $\alpha$ varies waveforms are shown in Figure 5(a), (b) and (c), respectively. It is worth noting that the bypass breakers of TCSCs are open at $1 \mathrm{~s}$ and TCSCs operate in their capacitor mode in the normal condition.

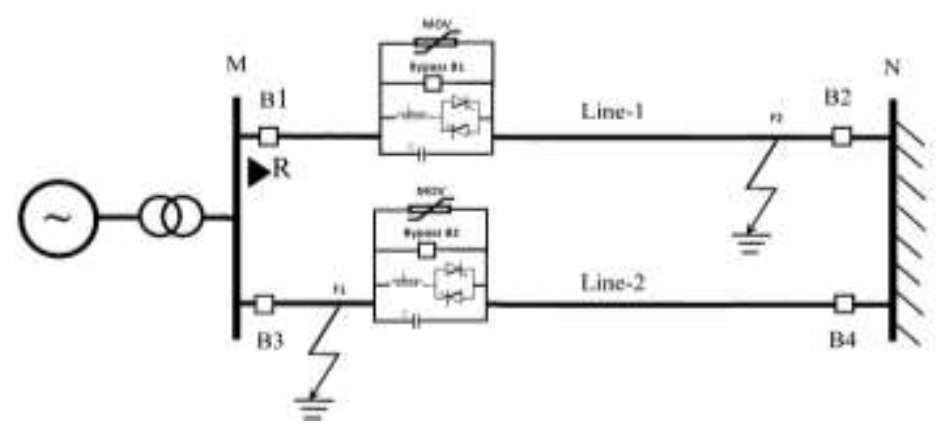

Figure 4. SMIB compensated by TCSC 


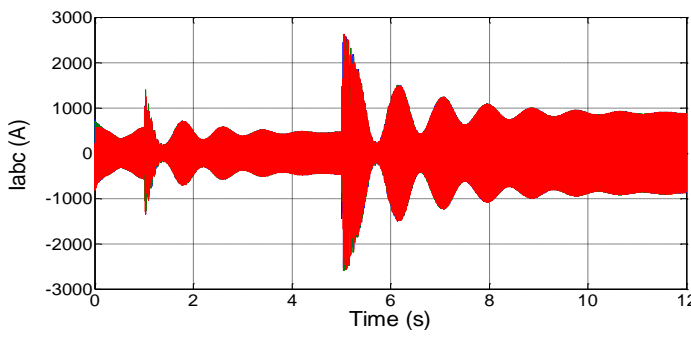

(a)

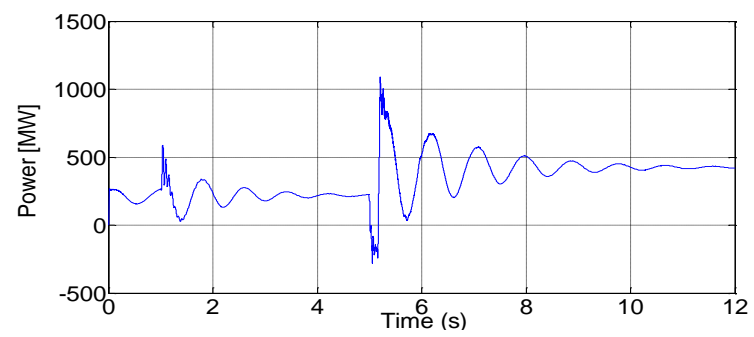

(b)

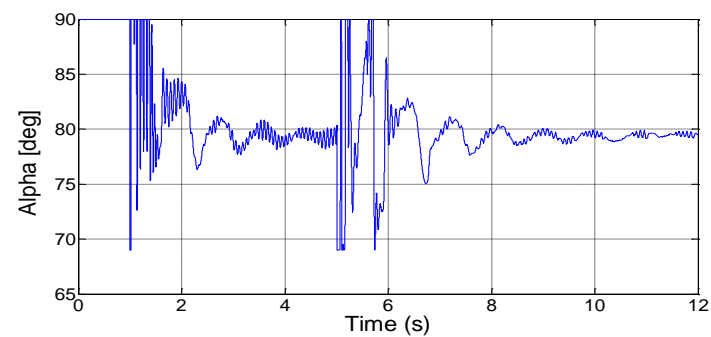

(c)

Figure 5. Operation of TCSC: (a) Power transfer by line 1, (b) Three phase current of line 1, (c) $\alpha$ varies of TCSC1

\subsection{Line-to ground fault in the TCSC-compensated line}

The algorithm is tested for a line-to-ground fault of ag-type with a fault resistance of $0.001 \Omega$ initiated at $5.6 \mathrm{~s}$ at a distance of $260 \mathrm{~km}$ from the relay location. The results are shown in Figure 6 . As an unbalanced fault, the $\mathrm{I}_{2}$ observed during the fault is significant. The index is zero before the inception of the fault and after that its value grows. The output " 1 " clearly shows that the fault is detected after $12 \mathrm{~ms}$ of fault initiation.

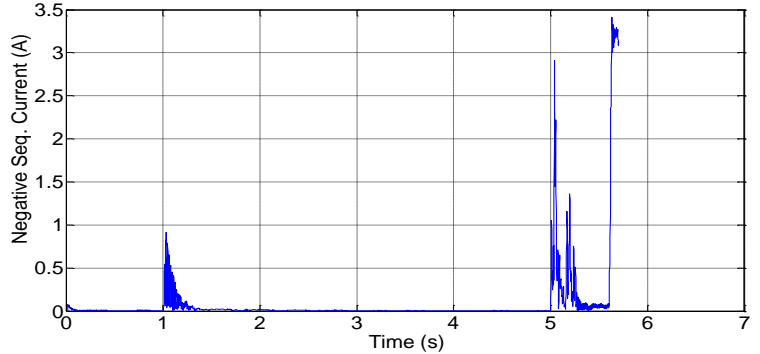

(a)

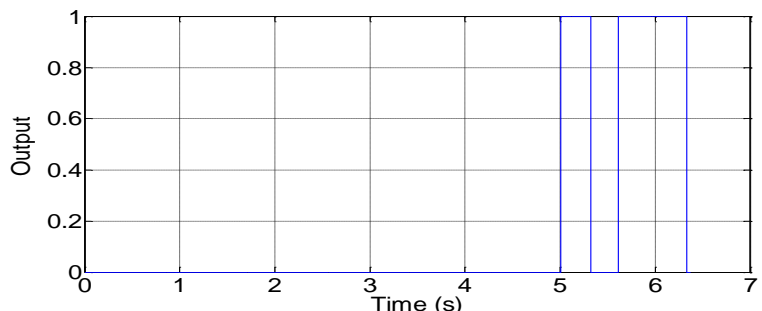

(c)

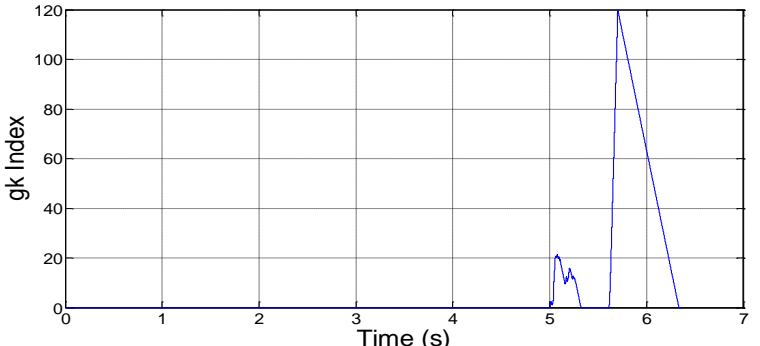

(b)

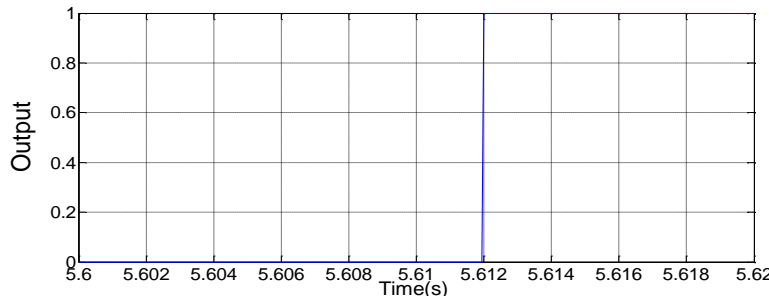

(d)

Figure 6. Results of an ag-fault: (a) Negative sequence current $\left(I_{2}\right)$ of Line 1 , (b) $g_{k}$ Index, (c) output, (d) Fault detection time

\subsection{Three-phase fault in the TCSC-compensated line}

The power swing and three-phase faults are balanced in nature. It is difficult to distinguish three-phase faults during the power swing. A three-phase fault created at 5.6s during the power swing at a distance of $260 \mathrm{~km}$ from the relay location in line-1 is used to test the algorithm. The results are shown 
in Figure 7.

In the initial period of a three-phase fault due to the transient in the current signals, $\mathrm{I}_{2}$ computed will not be zero. The index as the cumulative sum of $\Delta \mathrm{I}_{2}$, remains high following the transient also. As observed from the plot, the index $\mathrm{g}_{\mathrm{k}}$ computed is high after the inception of the fault and is zero before it. The output " 1 " in the plot clearly shows that the fault can be detected after $6 \mathrm{~ms}$ of fault inception.

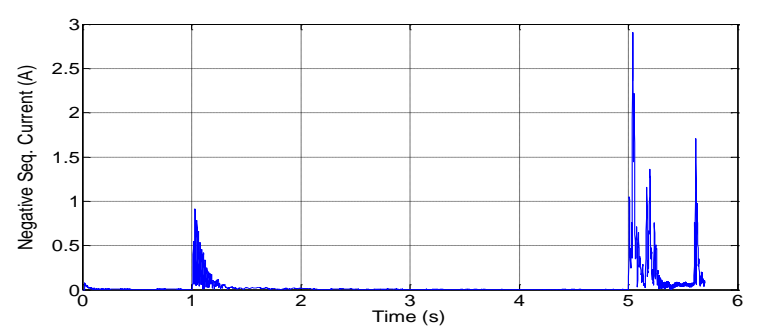

(a)

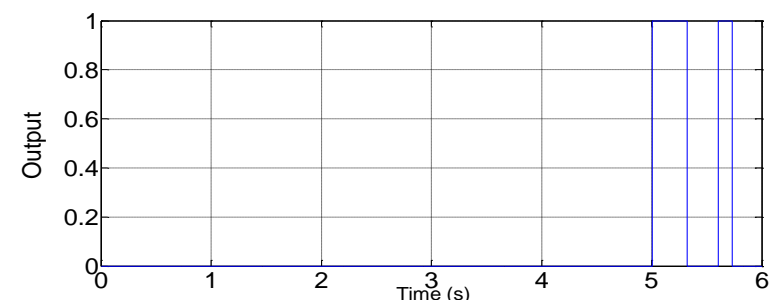

(c)

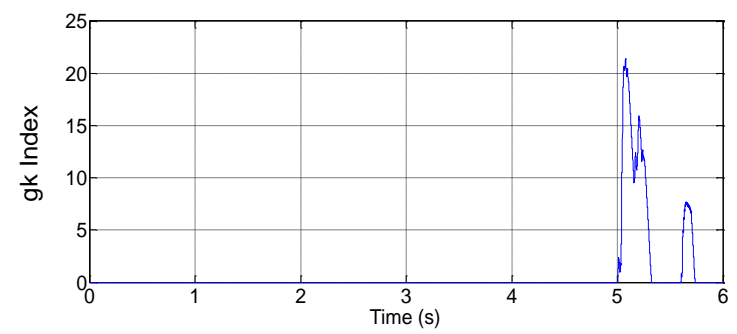

(b)

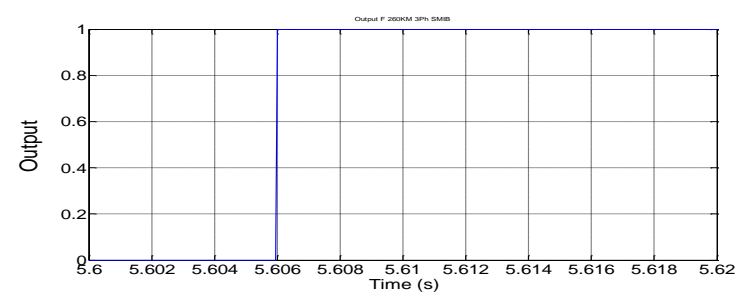

(d)

Figure 7: Three-phase fault. (a) Negative sequence current $\left(I_{2}\right)$ of Line 1, (b) $g_{k}$ Index, (c) Output of method, (d) Fault detection time

\subsection{Three phase fault with high fault resistance and $\delta \max$}

When $\delta$ is in its maximum value (close to 180 degree), the currents and voltages reach their maximum and minimum values respectively. If a fault occurs at that instant, the change in current and voltage signals will be insignificant. As a result, the detection of faults during $\delta$ close to 180 is a very difficult issue [14]. $\delta$ at $6.250 \mathrm{~s}$ is at its maximum value so it is the most difficult situation to detect fault, when a high resistance symmetrical three-phase fault occurs at $6.250 \mathrm{~s}$.

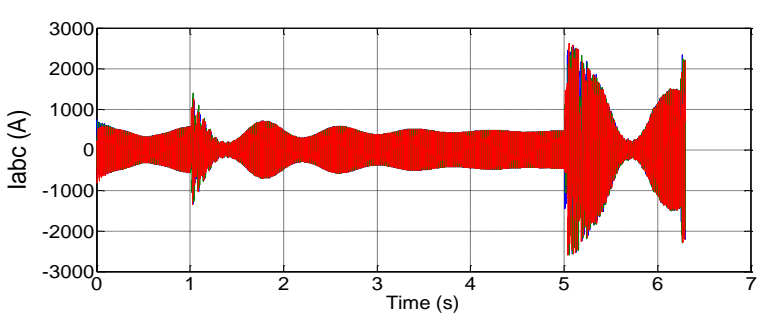

(a)

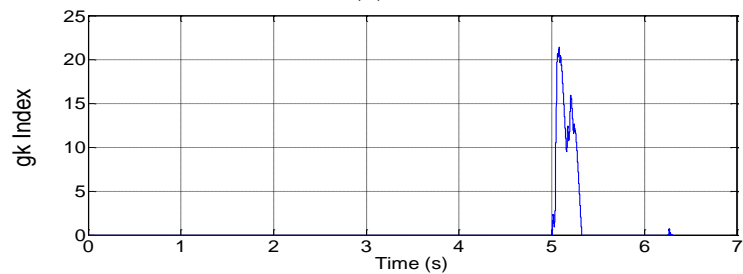

(c)

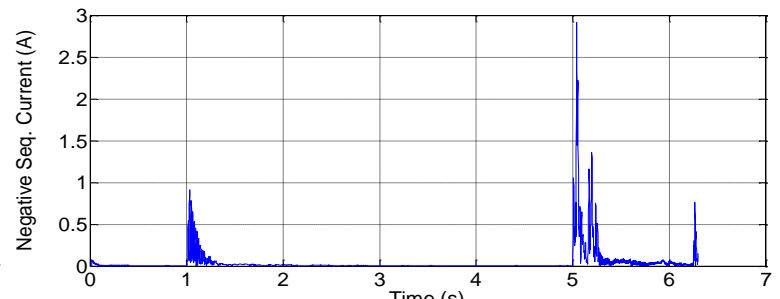

(b)

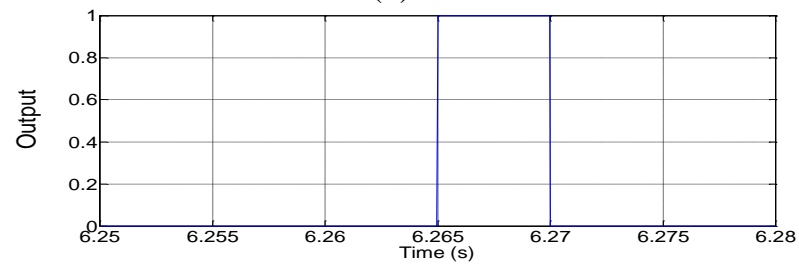

(d)

Figure 8. Three-phase fault with high fault resistance. (a) 3phase current Waveform of Line 1, (b) negative sequence current $\left(I_{2}\right)$ of Line 1 , (c) $g_{k}$ Index, (d) Fault detection time 
The results of the simulation of symmetrical three phase fault with a resistance of 50 ohms at a distance of $260 \mathrm{~km}$ from the relay location at 6.250s are shown in Figure 8. In such situation, the output "1" shows correct fault detection after $15 \mathrm{~ms}$ of fault initiation.

\subsection{Application to the multi-machine 9-bus system}

To test the ability of the proposed method for a multi machine power system compensated by TCSC, a 3-machine, 9-bus system [14], shown in Figure 9, is considered. Line 7-8 is 75\% compensated by TCSC at the mid-point of line. The protection scheme of the series capacitor simulated in this case consists of an MOV. The system details are given in Appendix B. The distance relay R1 for breaker B1 is considered for the study. A transient three-phase fault with $0.001 \Omega$ fault resistance is created on line 4-5 at $5 \mathrm{~s}$. The fault is cleared at $5.1 \mathrm{~s}$ by opening breakers B3 and B4. Afterwards B3 and B4 Breakers are closed at 5.25s by operation of recloser system. This causes a significant power swing condition for relay R1. The Transfer power by line 7-8, three phase current and the variation of $\alpha$ at relay R1 during the power swing are shown in Figure 10(a), (b) and (c), respectively. Different faults are simulated on line 7-8 to test the algorithm.

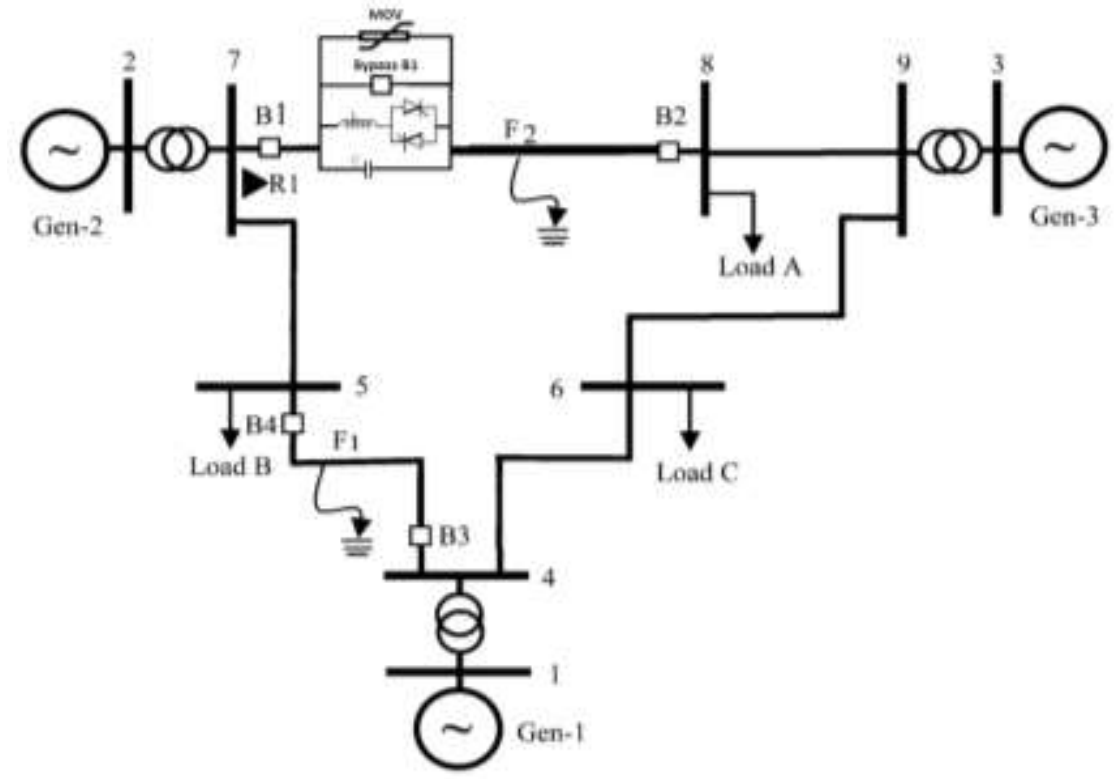

Figure 9.9 bus-3 machine system compensated by TCSC in line 7-8

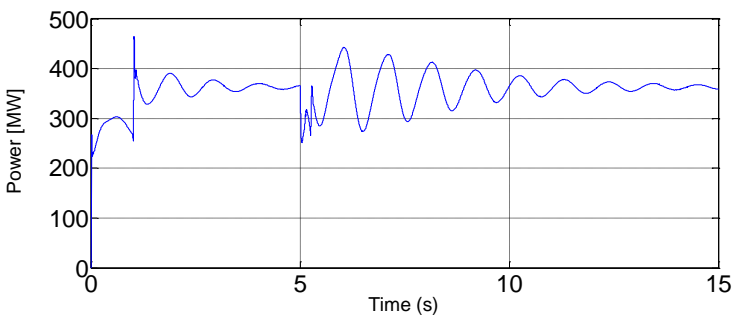

(a)

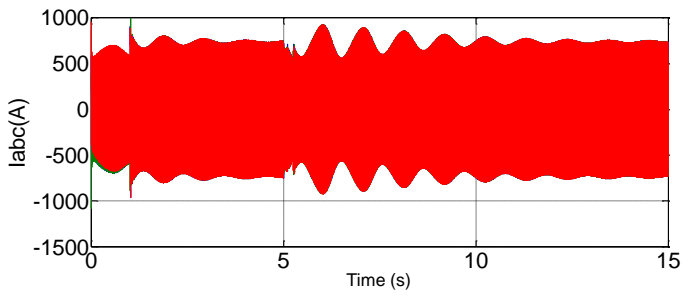

(b)

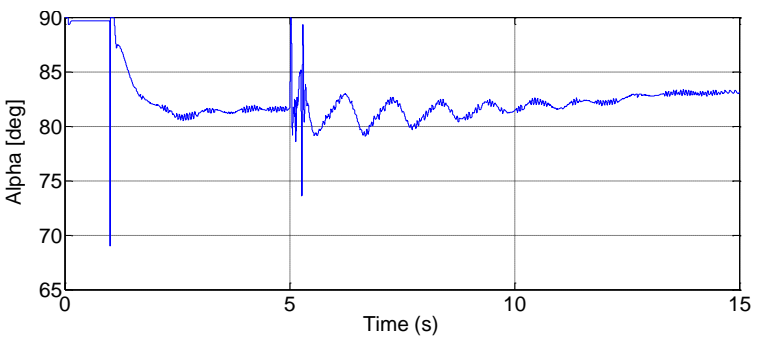

(c)

Figure 10. A transient three-phase fault with $0.001 \Omega$ fault resistance on line $4-5$ at $5 \mathrm{~s}$. (a) Power Transfer by Line 1, (b) three phase current of Line 1, (c) variation of $\alpha$ 


\subsection{Three-phase fault in the TCSC-compensated line}

A three-phase fault with $0.001 \Omega$ fault resistance is created at $5.6 \mathrm{~s}$ at a distance of $260 \mathrm{~km}$ from the relay location on line 7-8. The results are shown in Figure 11. The output "1" in the plot clearly shows that the fault can be detected after $6 \mathrm{~ms}$ of fault inception.

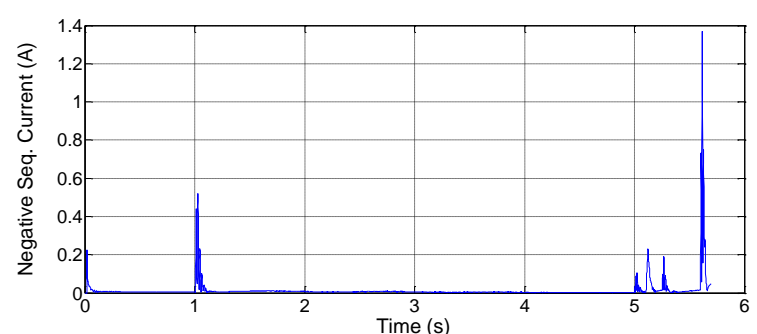

(a)

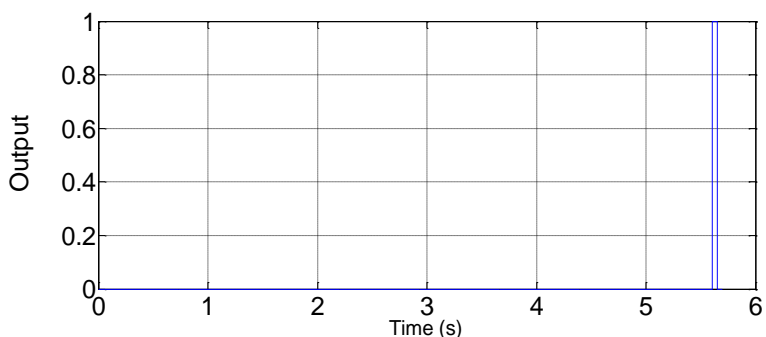

(c)

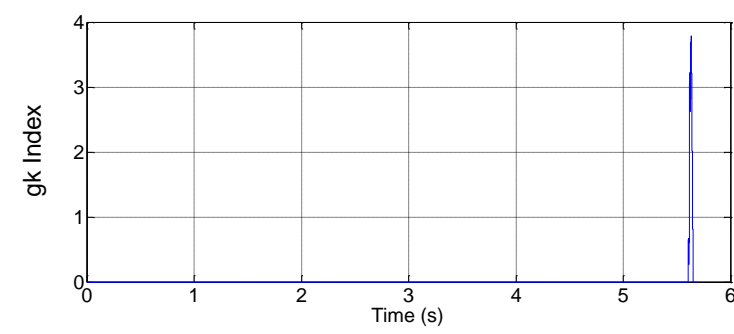

(b)

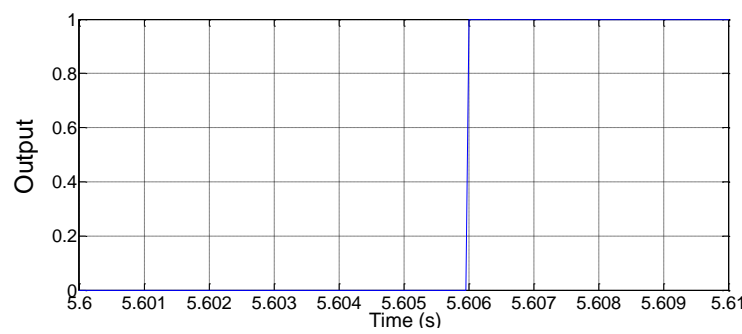

(d)

Figure 11. A transient three-phase fault with $0.001 \Omega$ fault resistance on line 7-8 at 5.6s. (a) negative sequence current $\left(I_{2}\right)$ of Line 7-8,(b) $g_{k}$ Index, (c) output of the method, (d) fault detection time.

\subsection{Three phase fault with high fault resistance}

To test the technique, a three phase fault with fault resistance $100 \Omega$ is initiated at $5.6 \mathrm{~s}$ during the power swing at a distance of $260 \mathrm{~km}$ from the relay location. The results are shown in Figure 12. The output "1" shows correct fault detection after $14 \mathrm{~ms}$ of fault initiation.

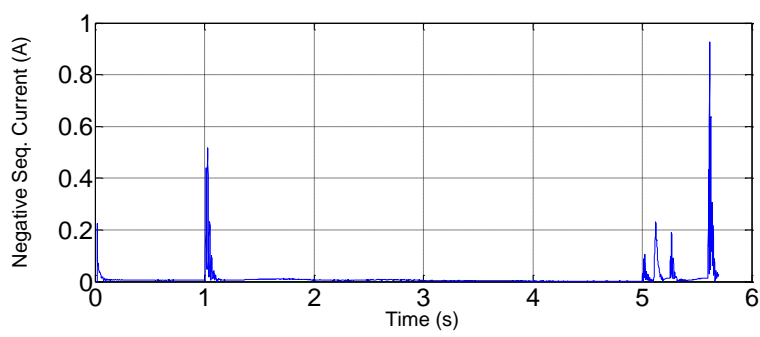

(a)

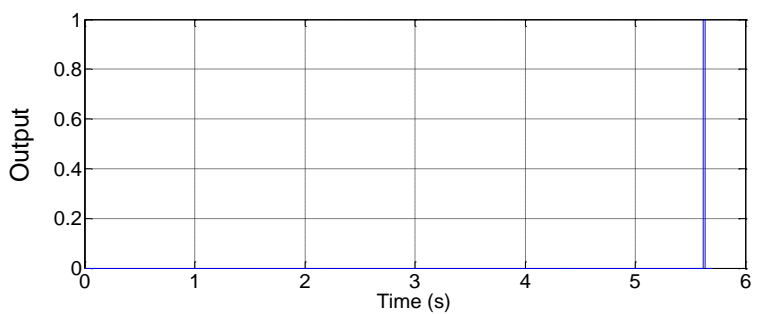

(c)

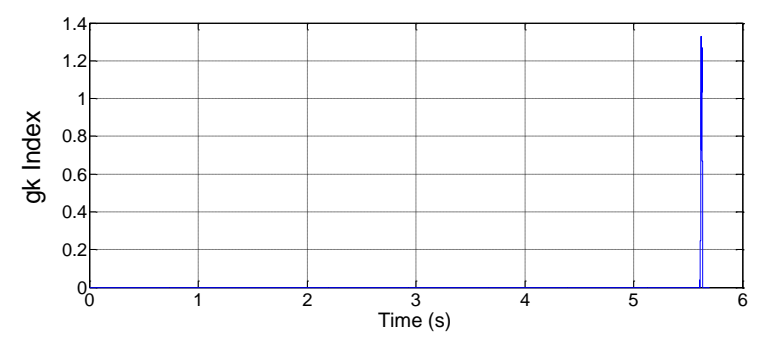

(b)

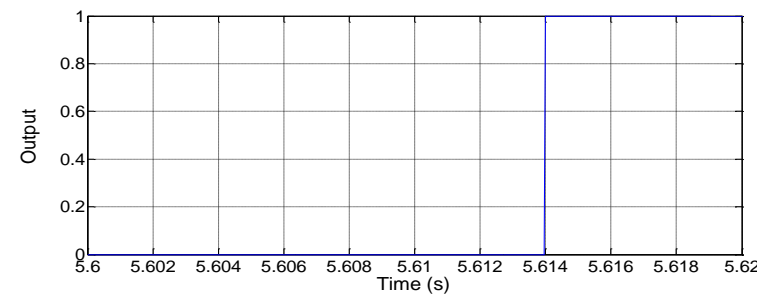

(d)

Figure 12: A transient three-phase fault with $0.001 \Omega$ fault resistance on line 7-8 at 5.6s. (a) negative sequence current $\left(I_{2}\right)$ of Line 7-8,(b) $g_{k}$ Index, (c) output of the method, (d) fault detection time 
3.7. Evaluation of the performance of the algorithm for fault detection during power swing in the inductor mode of TCSC due to high fault current

In order to evaluate the behavior of the proposed algorithm for detecting fault during power swing while the severity of the fault current causes a change in the application mode of TCSC (to inductor mode) a symmetrical three-phase fault with $0.001 \Omega$ resistance at a distance of $40 \mathrm{~km}$ from the relay location on line 87 is created. The simulation results are shown in Figure 13. Output "1" shows correct fault detection after 3 ms of the fault inception.

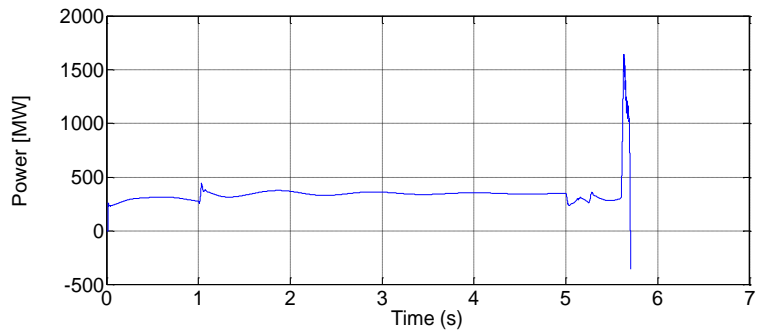

(a)

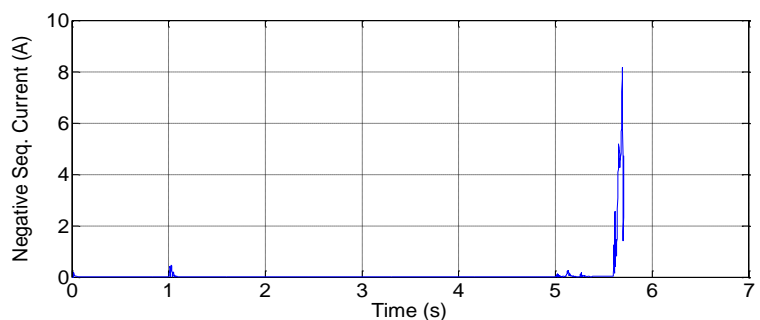

(c)

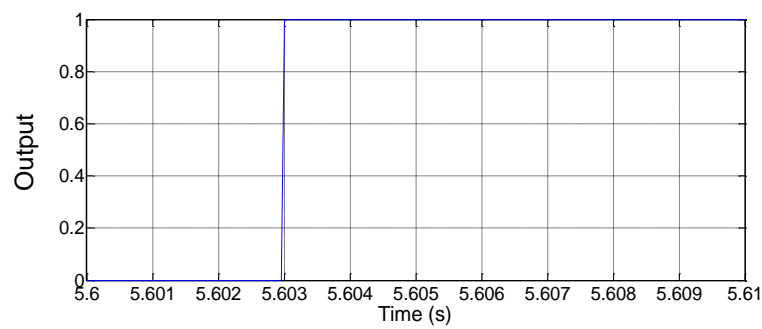

(e)

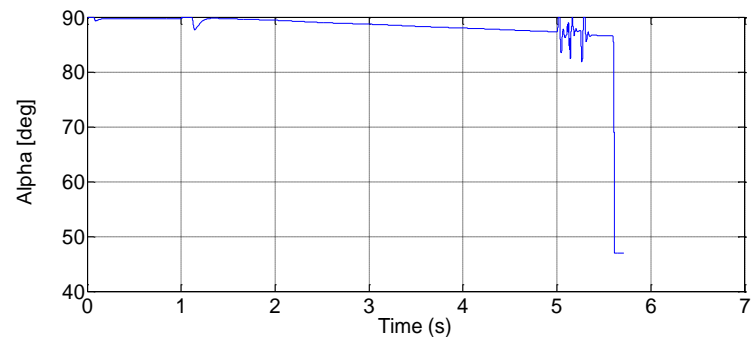

(b)

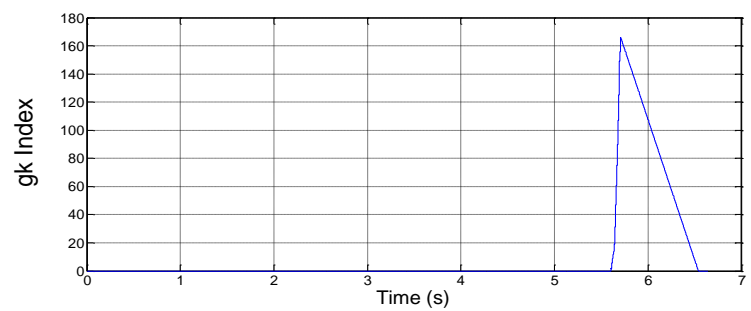

(d)

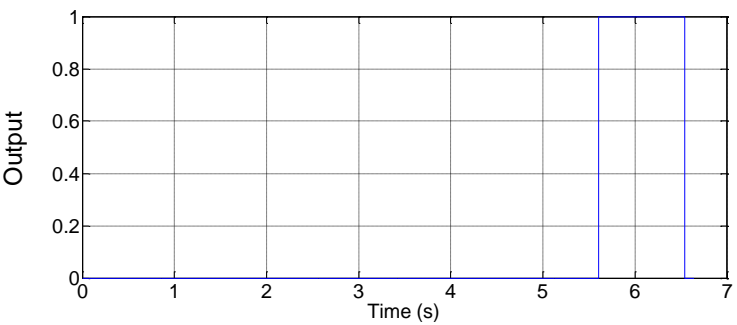

(f)

Figure 13. A three-phase fault during power swing on line 7-8 (a) Power Transfer by Line 7-8, (b) variation of $\alpha$, (c) negative sequence current $\left(I_{2}\right)$ of Line 7-8, (d) $g_{k}$ Index, (e) output of the method, (f) fault detection time

\section{CONCLUSION}

A method based on CUSUM of negative sequence current already proposed for fault detection during power swing in Series Capacitor compensated lines is extended for compensated lines by TCSC. Performance of the proposed algorithm for different symmetrical and asymmetrical faults in the compensated system by TCSC is analyzed and its accuracy and speed is evaluated. The advantages of this method are as follows:

a. High speed and high accuracy of this method for detecting different symmetrical and asymmetrical faults during power swing in compensated lines by TCSC.

b. The lack of sensitivity of the method to non-linear operation of the compensator and nonlinear varies reactance of the TCSC, as well as non-linear behavior of MOV in the fault and a power swing conditions.

c. The fast detection of high resistance faults during power swing even when the fault occurs at $\delta$ close to 180 degrees.

d. No dependency on configuration complexity or the need for widespread studies. 


\section{REFERENCES}

[1] P. K. Dash, A. K. Pradhan, G. Panda and A. C. Liew, "Digital protection of power transmission lines in the presence of series connected FACTS devices," 2000 IEEE Power Engineering Society Winter Meeting. Conference Proceedings (Cat. No.00CH37077), Singapore, 2000, pp. 1967-1972 vol.3.

[2] Wang Weiguo, Yin Xianggen, Yu Jiang, Duan Xianzhong and Chen Deshu, "The impact of TCSC on distance protection relay," POWERCON '98. 1998 International Conference on Power System Technology. Proceedings (Cat. No.98EX151), Beijing, China, 1998, pp. 382-388 vol.1.

[3] IEEE Power System Relaying Committee of the IEEE Power Eng. Soc., Power Swing and Out-of-Step Considerations on Transmission Line. Rep. PSRC WG D6, Jul. 2005. [Online]. Available: http://www.pes-psrc.org.

[4] A. Y. Abdelaziz, A. M. Ibrahim, M. M. Mansour, and H. E. Talaat, "Modern approaches for protection of series compensated transmission lines," Electric Power Systems Research, vol. 75, pp. 85-98, July 2005.

[5] Kulkarni P.A.,Holmukhe R.M.,Deshpande K.D.,Chaudhari P.S, "Impact of TCSC on Protection of Transmission Line," Proceedings of International Conference on Energy Optimization and Control. Aurangabad, Maharashtra, Dec. 28-30, 2010, pp. 3-7.

[6] G. Benmouyal,D. Hou, andD. Tziouvaras, "Zero-setting power-swing blocking protection," presented at the the 31 st Annual Western Protective Relay Conf., Spokane, WA, Oct. 2004.

[7] A. Mechraoui and D. W. P. Thomas, "A new principle for high resistance earth fault detection during fast power swings for distance protection," in IEEE Transactions on Power Delivery, vol. 12, no. 4, pp. 1452-1457, Oct. 1997.

[8] A. P. Apostolov, D. Tholomier and S. H. Richards, "Superimposed components based sub-cycle protection of transmission lines," IEEE PES Power Systems Conference and Exposition, 2004., New York, NY, 2004, pp. 592597 vol.1.

[9] Z. D. Gao and G. B. Wang, "A new power swing block in distance protection based on a microcomputer-principle and performance analysis," 1991 International Conference on Advances in Power System Control, Operation and Management, APSCOM-91., Hong Kong, 1991, pp. 843-847 vol.2.

[10] X. Lin, Y. Gao and P. Liu, "A Novel Scheme to Identify Symmetrical Faults Occurring During Power Swings," in IEEE Transactions on Power Delivery, vol. 23, no. 1, pp. 73-78, Jan. 2008.

[11] S. Lotfifard, J. Faiz and M. Kezunovic, "Detection of Symmetrical Faults by Distance Relays During Power Swings," in IEEE Transactions on Power Delivery, vol. 25, no. 1, pp. 81-87, Jan. 2010.

[12] H. K. Zadeh and Z. Li, "A novel power swing blocking scheme using adaptive neuro-fuzzy inference system," Electric Power Systems Research, vol.78, no. 7, pp. 1138-1146, 2008.

[13] A. Esmaeilian, A. Ghaderi, M. Tasdighi and A. Rouhani, "Evaluation and performance comparison of power swing detection algorithms in presence of series compensation on transmission lines," 2011 10th International Conference on Environment and Electrical Engineering, Rome, 2011, pp. 1-4.

[14] P. K. Nayak, A. K. Pradhan and Prabodh, "Detecting fault during power swing for a series compensated line," 2011 International Conference on Energy, Automation and Signal, Bhubaneswar, Odisha, 2011, pp. 1-6.

[15] N .G .Hingorani, Laszlo Gyugyi, "Understanding FACTS", IEEE Press, 2001, pp 223-238.

[16] S. Meikandasivam, R. K. Nema and S. K. Jain, "Selection of TCSC parameters: Capacitor and inductor," India International Conference on Power Electronics 2010 (IICPE2010), New Delhi, 2011, pp. 1-5.

[17] F. Gustafsson, Adaptive Filtering and Change Detection. New York: Wiley, 2000.

[18] S. R. Mohanty, A. K. Pradhan and A. Routray, "A Cumulative Sum-Based Fault Detector for Power System Relaying Application," in IEEE Transactions on Power Delivery, vol. 23, no. 1, pp. 79-86, Jan. 2008.

\section{APPENDIX}

\subsection{System data for SMIB:}

\subsubsection{Generator:}

$\mathrm{Pn}=600 \mathrm{MW}, \mathrm{Vn}=22 \mathrm{KV}, \mathrm{fn}=50 \mathrm{~Hz}$

$\mathrm{Xd}=1.305, \mathrm{Xd}^{\prime}=0.296, \mathrm{Xd}=0.252, \mathrm{Xq}=0.474, \mathrm{Xl}=0.18(\mathrm{Pu})$

$\mathrm{Td}=1.01, \mathrm{Td}=0.053, \mathrm{Tq} 0 "=0.1(\mathrm{~s})$

Stator Resistance Rs=0.0028544 (Pu)

Inertia Coefficient: $\mathrm{H}(\mathrm{s})=3.7$, Friction Factor $\mathrm{F}(\mathrm{Pu})=0$, Pole pairs $\mathrm{P}=32$

5.1.2 Transformer:

Winding 1:

Connection: Delta (D1), Vph-ph=22KV, R=0.000885(Pu), L=0.0815(Pu)

Winding 2:

Connection: Yg, Vph-ph=400 KV , R=0.000885(Pu) , L=0.0815(Pu)

$\mathrm{Pn}=600 \mathrm{MW}, \mathrm{fn}=50 \mathrm{~Hz}$

Magnetization resistance $\mathrm{Rm}(\mathrm{pu})=100$

Magnetization inductance $\mathrm{Lm}(\mathrm{pu})=100$

5.1.3 Transmission lines:

Length $=320 \mathrm{Km}$

$\mathrm{Fn}=50 \mathrm{~Hz}$

Resistance per unit length $(\mathrm{Ohms} / \mathrm{km}): \mathrm{R} 1=0.12, \mathrm{R} 0=0.039$

Inductance per unit length $(\mathrm{H} / \mathrm{km}): \mathrm{L} 1=0.0028, \mathrm{~L} 0=0.0041$ 


\subsection{System data for 3-machine 9-bus configuration}

5.2.1 Generators:

Gen 1: $\mathrm{Pn}=600 \mathrm{MW}, \mathrm{Vn}=22 \mathrm{kV}, \mathrm{fn}=50 \mathrm{~Hz}$

Gen2: $\mathrm{Pn}=565 \mathrm{MW}, \mathrm{Vn}=22 \mathrm{kV}, \mathrm{fn}=50 \mathrm{~Hz}$

Gen3: $P n=410 \mathrm{MW}, \mathrm{Vn}=22 \mathrm{kV}, \mathrm{fn}=50 \mathrm{~Hz}$

5.2.2 Transformers:
T1: $600 \mathrm{MVA}, 22 / 400 \mathrm{kV}, 50 \mathrm{~Hz}$
T2: $565 \mathrm{MVA}, 22 / 400 \mathrm{kV}, 50 \mathrm{~Hz}$
T3: 410 MVA, $22 / 400 \mathrm{kV}, 50 \mathrm{~Hz}$

5.2.3 Transmission lines:

Length of line 7-8: $320 \mathrm{Km}$

Length of line 8-9: 400Km

Length of line 7-5: $310 \mathrm{Km}$

Length of line 5-4: $350 \mathrm{Km}$

Length of line 6-4: $350 \mathrm{Km}$

5.2.4 Loads:

Length of line 6-9: $300 \mathrm{Km}$

Load A: 500MW +50MVAR

Load B: 300MW +30MVAR

Load C: 400MW +30MVAR

The other parameters considered for generators, transformers, and transmission lines are the same as that provided for SMIB.

\section{BIOGRAPHIES OF AUTHORS}

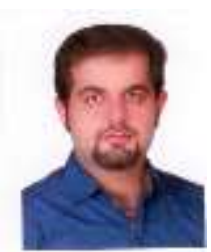

He was born in Iran in1987. He received his B.Sc and M.Sc. degrees in electrical engineering from Islamic Azad University of Saveh, Saveh, Iran in 2009 and 2014 respectively.

(e-mail: saeedrezaei2255@gmail.com).

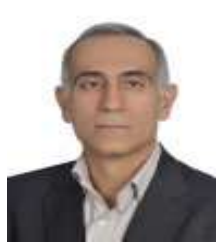

Mojtaba Khederzadeh is with the Faculty of Electrical Engineering Department, Shahid Beheshti University, A.C., Tehran 1658953571, Iran (e-mail: Khederzadeh@ pwut.ac.ir). He was born in Iran in 1957. He received his B.Sc and M.Sc. and PhD degrees in electrical engineering from Sharif University of Technology, Tehran, Iran 1980 and 1990 and 1996 respectively.

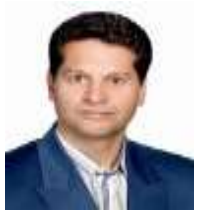

Majid Gandomkar is with the Faculty of Electrical Engineering Department, Islamic Azad University of Saveh, Saveh, Iran (e-mail: gandomkar-m@yahoo.com). He was born in Iran in1973. He received his B.Sc and M.Sc. degrees in electrical engineering from Sharif University of Technology 1995 and 1997 respectively and $\mathrm{PhD}$ degree in electrical engineering from Science and Research Campus, Tehran, Iran. 